\title{
DIETARY HABITS AND PREVALENCE OF RECURRENT ABDOMINAL PAIN IN SCHOOL CHILDREN IN PERIPHERY OF KANPUR CITY
}

Ravi Prakash Agrawal' ${ }^{1}$, Chandra Madhur Sharma ${ }^{2}$.

1. Assistant Professor, Department of Pediatrics, Rama Medical College \& Research Center, Kanpur.

2. Assistant Professor, Department of Pediatrics, Rama Medical College \& Research Center, Kanpur.

\section{CORRESPONDING AUTHOR}

Dr. Ravi Prakash Agrawal,

Flat no.207, second staff accommodation,

Rama medical college and research center,

Mandhna, Kanpur- 209217,

Uttar Pradesh, India.

Email- agrawalraviprakash@gmail.com

\section{HOW TO CITE THIS ARTICLE:}

Ravi Prakash Agrawal, Chandra Madhur Sharma. "Dietary habits and Prevalence of Recurrent Abdominal Pain in School Children in Periphery of Kanpur city". Journal of Evolution of Medical and Dental Sciences 2013; Vol2, Issue 26, July 1; Page: 4719-4724.

ABSTRACT: - BACKGROUND: Even though childhood RAP (recurrent abdominal pain) is a worldwide problem, very few epidemiological studies had been done to correlate RAP with dietary habits. Our objective is to determine the dietary habits and prevalence of RAP in school children of village in periphery of Kanpur city. MATERIAL AND METHOD: In this cross-sectional study we select an aided school of a village in periphery of Kanpur city. Written consent was obtained from parents along with pretested semi structured parental questionnaire which were distributed in first week of July 2012 through school authorities and collected in similar fashion in last week of July 2012. RESULT: Frequent drinking of soft drink was $32.89 \%$ and $16.78 \%$ in children with RAP and without RAP respectively. Fruit intake was significantly low in our study in both groups $7.89 \%$ vs.10\% in controls). Skipping of diet is an important factor in our study $(18.42 \%$ vs. $9.10 \%$ in controls).no significant difference is seen on parameters of drinking tea, fast food/junk food intake and their bowel habits in this study. CONCLUSION: In this study prevalence of RAP was significantly associated with frequent drinking of soft drinks, students with high soft drink consumption reported low fruit intakes. Consumption of more healthful beverages, such as milk, curd or water, should be encouraged at home and at meals consumed away from home.

KEY WORDS: recurrent abdominal pain, soft drink, school students.

INTRODUCTION: Abdominal pain is a symptom and not a diagnosis. Recurrent abdominal pain (RAP) in children was defined by Apley as "at least three episodes of abdominal pain severe enough to affect daily activities over a period longer than three months" ${ }^{1}$. The prevalence of RAP in childhood ranges between $10 \%$ to $20 \%{ }^{1,2}$. The incidences of organic and non-organic causes of RAP are variable in different studies ${ }^{13}$, 4 . Even though childhood RAP is a worldwide problem, very few epidemiological studies had been done to correlate RAP with dietary habits ${ }^{19}$. Our objective is to 


\section{ORIGINAL ARTICLE}

determine the dietary habits and prevalence of RAP in school children of village in periphery of Kanpur city.

SUBJECTS AND METHODS: In this study we select an aided school of a village in periphery of Kanpur city. In this schools survey students are chosen from academic years one to nine. All students aged five to fourteen years were included in the study. Written consent was obtained from parents along with pretested semi-structured parental questionnaire were distributed in first week of July 2012 through school authorities and collected in similar fashion in last week of July 2012. Information regarding demographic features, dietary habits, clinical details of abdominal pain, a history of RAP among first-degree relatives and health care consultation in last six months was obtained. Recurrent abdominal pain was defined using Apley's criteria. During analysis, 560 children without recurrent abdominal pain were considered as controls.

\section{RESULTS}

PREVALENCE OF RECURRENT ABDOMINAL PAIN: Six hundred and eighty nine children were eligible for the study. Out of them 680 parents consented to participate. A total of 636 questionnaires were returned out of these 680 parents. All of them were included in our study. This included 334 males and 302 females. Seventy six children fulfilled the criteria for diagnosis of recurrent abdominal pain. Prevalence of RAP in males was 12.57\% (42 out of 334) and in female $11.25 \%$ (34 out of 302). In our study Incidence of RAP decreases with age especially in females. (Table 1)

TABLE- 1: Demographic profile of study population

\begin{tabular}{|l|l|l|}
\hline Age group & Male prevalence & Female prevalence \\
\hline 5 to 10 year & $24(13.40 \%) n=179$ & $22(13.41 \%) n=164$ \\
\hline 10 to 14 year & $18(10.90 \%) n=165$ & $12(8.69 \%) n=138$ \\
\hline Total & $42(12.57 \%) n=334$ & $34(11.25 \%) n=302$ \\
\hline
\end{tabular}

CLINICAL PROFILE OF AFFECTED CHILDREN: Abdominal pain was defined as mild when the child was able to walk about and carry out regular activities during episodes of pain and as moderate when the child needed to sit down. Pain was classified as severe if the child had to lie down during pain episodes. The majority of the affected children had mild to moderate abdominal pain 58 $(76.31 \%)$ and severe in $18(23.68 \%)$. The commonest pattern of abdominal pain was recurrent episodes of periumbilical pain $40(52.68 \%)$ followed by $17(22.36 \%)$ and $7(9.21 \%)$ had pain in upper and lower abdomen respectively. Rest $12(15.78 \%)$ had no specific site for pain. Pain was mostly steady, non-radiating in character, each lasting ten minutes to one hour with no specific aggravating or relieving factors.

History of pain in abdomen in first degree relatives of our study population was 22 (28.94\%) vs. $93(16.60 \%)$ in controls. 


\section{ORIGINAL ARTICLE}

DIETARY HABITS OF STUDY POPULATION: In contrast to the common belief that RAP is associated with low fiber diet, this study failed to demonstrate significant associations between RAP and non vegetarian diet (9.22\% vs.13.04\% in controls).

Frequent drinking of soft drink was $32.89 \%$ and $16.78 \%$ in children with RAP and without RAP respectively. While there was slight difference in sometime drinking habit $(47.36 \%$ vs. $50 \%$ in controls). (Table-2)

Fruit intake was significantly low in our study in both groups (7.89\% vs.10\% in controls). Skipping of diet was an important factor in our study (18.42\% vs. $9.10 \%$ in controls). No significant difference was seen on parameters of drinking tea, fast food/junk food intake and their bowel habits in this study. (Table-3)

TABLE -2: Carbonated soft drink intake habits

\begin{tabular}{|l|l|l|}
\hline & RAP & Without RAP \\
\hline Frequent drinking & $25(32.89 \%)$ & $94(16.78 \%)$ \\
\hline Sometime drinking & $36(47.36 \%)$ & $280(50 \%)$ \\
\hline No/less drinking & $15(19.73 \%)$ & $186(33.21 \%)$ \\
\hline total & $\mathbf{7 6}$ & $\mathbf{5 6 0}$ \\
\hline
\end{tabular}

Frequent drinking-100 to $200 \mathrm{ml} 3$ times /week or more Sometime drinking- 100 to $200 \mathrm{ml}$ less than 3 times /week No/less drinking-0 to $100 \mathrm{ml}$ less than 3 times /week

TABLE-3 Dietary habits of study population

\begin{tabular}{|c|c|c|}
\hline & $\operatorname{RAP}(n=76)$ & Without RAP $(n=560)$ \\
\hline Vegetarian diet* & $69(90.78 \%)$ & $487(86.96 \%)$ \\
\hline Tea drinking ${ }^{* *}$ & $23(30.26 \%)$ & $134(23.92 \%)$ \\
\hline Fruit intake ${ }^{* * *}$ & $06(7.89 \%)$ & $56(10 \%)$ \\
\hline Fast food/junk food ${ }^{* * * *}$ & $16(21.05 \%)$ & $90(16.07 \%)$ \\
\hline Diet skipping\# & $14(18.42 \%)$ & $51(9.10 \%)$ \\
\hline Irregular bowel $\# \#$ & $11(14.47 \%)$ & $62(11.07 \%)$ \\
\hline
\end{tabular}

Vegetarian diet includes milk but not the egg*.

Tea drinking - 75 to150ml 3 times /day or more included in study**.

Fruit 3 times/ week or more as snack ${ }^{* * *}$.

Fast food (noodles, burger etc.) 3 times/week or more ${ }^{* * * *}$.

Diet skipping 3 times/week or more\#.

Irregular bowel 3 days/week or more \#\#.

HEALTH CARE CONSULTATION IN CHILDREN WITH RAP IN LAST SIX MONTHS: Sixty seven (88.15\%) children with RAP had consulted a doctor during the last six months .out of them, only three $(4.47 \%)$ had history of hospitalization and the rest sixty four $(95.52 \%)$ were managed as outpatient basis. 


\section{ORIGINAL ARTICLE}

DISCUSSION: The prevalence of RAP among children in our study was similar to those previously reported. In 1958, Apley and Naish reported a prevalence of 10.8\% among British schoolchildren, with girls (12.3\%) more commonly affected than boys (9.5\%) ${ }^{1}$, while in our study boys $(12.57 \%)$ were more affected then girls(11.25\%). More recent studies in Western countries and in Asia have reported similar prevalence; e.g. 11.8\% in British children ${ }^{9}, 12 \%$ in Australian children6, 11.5\% among schoolchildren in Bangladesh ${ }^{7}$ and $10.2 \%$ in urban and rural school children in Malaysia

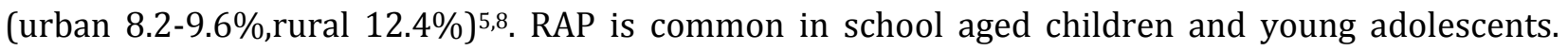
Prevalence of RAP was high in children between 5 to 10 year in our study population, which is in agreement with previous studies ${ }^{10,11}$. Majority of the affected children had mild to moderate abdominal pain (76.31\%), and in majority (52.68\%) pain was felt in periumbilical region and similar results have been reported from other countries $1,6,7$.

We found an independent association between RAP and the presence of abdominal pain among first degree relatives $(28.94 \%$ vs $16.60 \%)$. This was a finding which was less as compared to previous studies ${ }^{1,7}$. Specified time period (six month) for history of pain in abdomen and probably small family size were the main reasons, which was not specified in previous studies. This may also be due to genetic or environmental vulnerability, and further studies should be directed at identifying a definite genetic predisposition.

Dietary fiber is often low in the Western diet. Supplementing this has been evaluated in a small randomized, double-blind placebo-controlled trial of 52 children in a primary care setting. More children in fiber-supplemented group (13/26) had fewer episodes of pain than those with placebo $(7 / 26)$, an effect that reached statistical significance ${ }^{19}$, but in our study majority of the families were vegetarian in both groups (RAP vs. control).

One study of Gwalior city reported higher consumption of soft drink than the present study because of inclusion of private school children also who had statistically more consumption rate ${ }^{17}$, .one another study reported high socioeconomic status was positively associated with intake of soft drinks ${ }^{16}$.

Majority of children in our study take soft drink in high quantity with reduced fruit intake as reported in previous studies ${ }^{18}$. Perhaps sweetened beverage consumption is a marker for poor dietary habits or reflects meal sources with few fruit selections ${ }^{18}$. Previous study of western country reported Fruit consumption was approximately 57\% lower for those students in the highest tertile of soft drink consumption and 62\% lower (one half serving) in the highest tertile of sweetened beverage consumption, compared with fruit consumption by those in the lowest tertiles ${ }^{18}$.

The health care consultation in our study was higher $(88.15 \%)$ than that of previously reported $(8 \%, 34.0 \%, 45 \%, 48 \%$ and $70.1 \%)$ different studies $6,12,13,14,15$. Availability of free health services and easy access to health care and probably small family size had contributed to the higher prevalence of health care consultation in our study.

Previous studies have shown significant associations between health care consultation and age of onset, severity, frequency and duration of pain episodes, school absenteeism, sleep interruption and disruption of normal activity 12,13,14. As in our study the consultation rate was $88.15 \%$, there was no significant association between the health care consultation and sex, younger age, pain severity, sleep Interruption, family income, maternal employment, family size, school 


\section{ORIGINAL ARTICLE}

absenteeism, age of onset of RAP and frequency and duration of the pain episodes, which is consistent with another study 15.

Limitations of this study include the fact that dietary data were self-reported and the limited generalizability of the sample (first- to ninth-grade students from one school). The cross-sectional nature of the data limits our ability to attribute causality (e.g., choosing soft drink reduces fruit intake). Future research should determine whether similar differences exist in other population children's habits with RAP. In this study, students with high soft drink consumption reported low fruit intakes. Consumption of more healthful beverages, such as milk, curd or water, should be encouraged at home and at meals consumed away from home.

\section{REFERENCES:}

1. Apley J, Naish N, Recurrent abdominal pain. A field survey of 1000 school children. Arch Dis Child 1958; 33: 165-170.

2. Faull C, Nicol AR, Abdominal pain in six year olds: An epidemiological study. J Child Psychol Psychiatr 1986; 27: 251-260.

3. Dutta S, Mehta M, Verma IC. Recurrent abdominal pain in Indian Children and its relation with school and family environment. Indian Pediatr 1999; 36: 917- 920.

4. Balani B, Patwari AK, Bajaj P, Diwan N, Anand VK. Recurrent abdominal pain - A reappraisal. Indian Pediatr 2000; 37: 876-881.

5. Boey C, Yap S, Goh KL. The prevalence of recurrent abdominal pain in 11- to 16-year-old Malaysian schoolchildren. J Paediatr Child Health 2000; 36(2): 114-6.

6. Huang RC, Plamer LJ, Forbes DA. Prevalence and pattern of childhood abdominal pain in an Australian general practice. J Paediatr Child Health 2000; 36(4): 349-53.

7. Rasul CH, Khan MAD. Recurrent abdominal pain in school children in Bangladesh. Journal of the Ceylon College of Physicians 2000; 33:110-4.

8. Boey CC, Goh KL. Predictors of recurrent abdominal pain among 9 to 15-year-old urban school children in Malaysia. Acta Paediatr2001; 90(3): 353-5.

9. Ramchandani PG, Hotopf M, Sandhu B, SteinA. The epidemiology of recurrent abdominal pain from 2 to 6 years of age: results of a large, population-based study. Pediatrics 2005; 116(1): 46-50.

10. Niyaz A. Buch, Sheikh Mushtaq Ahmad, S. Zubair Ahmad, Syed Wajid Ali, B.A. Charoo and Masood-ul-Hassan Indian Pediatrics 2002; 39:830-834

11. Wyllie R, Kay M. Causes of recurrent abdominal pain. Clin Pediatr (Phila) 1993; 32(6): 36971.

12. Boey CCM, Goh KL. Predictors of health care consultation for recurrent abdominal pain among urban school children in Malaysia. J Gastroenterol Hepatol 2001; 16(2): 154-9.

13. Boey CCM, Goh KL. Recurrent abdominal pain and consulting behaviour among children in a rural community in Malaysia. Dig Liver Dis 2001; 33(2): 140-4.

14. Hyams JS, Burke G, Davis PM, Rzepski B, Anbrulons PA. Abdominal pain and irritable bowel syndrome in adolescents: a community based study. J Pediatr 1996; 129(2): 220-6.

15. Devanarayana NM, de Silva DG, de Silva HJ. Recurrent abdominal pain syndrome in a cohort of Sri Lankan children and adolescents: J Trop Pediatr 2008; 54(3): 178-83. 


\section{ORIGINAL ARTICLE}

16. Shi Z, Lien N, Kumar BN, Holmboe- Ottesen G. Socio-demographic differences in food habits and preferences of school adolescents in Jiangsu Province, China. Eur J Clin Nutr. 2005Dec; 59(12):1439-48.

17. Gour N, Srivastava D, Adhikari P. Study to Assess the Prevalence of Soft Drinking and its Determinants among the School going Children of Gwalior city. Online J Health Allied Scs. 2010; $9(2): 5$

18. Karen Weber Cullen, , Danielle M. Ash, Carla Warneke, Carl De Moor, intake of soft drinks, fruit-flavored beverages, and fruits and vegetables by children in grades 4 through 6 am j public health. 2002 September; 92(9): 1475-1477

19. Feldman W, McGrath P, Hodgson C, Ritter H, Shipman RT. The use of dietary fiber in the management of simple, childhood, idiopathic, recurrent, abdominal pain. Results in a prospective, double-blind, randomized, controlled trial. Am J Dis Child 1985; 139: 12161218. 